\title{
Information Requirements and Sharing for NGATS Function Allocation Concepts
}

\author{
Nhut Tan $\mathrm{Ho}^{1}$, Patrick Martin ${ }^{2}$, Joseph Bellissimo ${ }^{2}$, and Barry Berson ${ }^{2}$ \\ ${ }^{1}$ California State University Northridge (CSUN), Dept of Mechanical Engineering \\ ${ }^{2}$ CSUN Dept of Human Factors and Applied Psychology \\ 18111 Nordhoff Street, Northridge, CA 91330-8348, USA \\ \{nhut tho, patrick.martin.855, joseph.bellissimo.51\}@csun.edu
}

\begin{abstract}
To support the evaluation of feasible function allocation concepts for separation assurance systems, and to develop a better understanding of the specific information requirements for key tasks (resolving conflicts, avoiding weather, and merging and spacing), air traffic controllers and commercial pilots were interviewed for their goals, sub-goals, and the individual and shared information needed to perform the tasks. The key information requirements obtained can be used as input to ascertain which information is most needed for probing when measuring individual and shared situation awareness. The elicitation also provided insights into the interaction among the controllers, pilots, and automation, and their perception of the concepts' feasibility.
\end{abstract}

Keywords: information requirements, NGATS, allocation function, shared situation awareness, automation interaction.

\section{Introduction}

In the next two decades, the air traffic in the National Airspace System (NAS) is projected to increase two to three fold. To accommodate this growth, transformations in the air traffic management (ATM) architecture and operational concepts have been proposed for implementation in the NAS under the Next Generation Air Transportation System (NGATS) by 2005 [1], [2]. Some of the new NGATS key capabilities include: 1) trajectory-based operations (TBO) that enable users to dynamically assess changes in four-dimensional trajectories and allocate the resources to meet their demands; and 2) advanced net-centric and shared situational awareness (SA) systems for providing and sharing real-time weather, traffic, and flight information among all users. TBO implementation assumes that automation will take on a larger role in managing real-time operations, and that air traffic control shifts from tactical control of individual aircraft to strategic management of traffic flow and separation, while tactical separation assurance may be delegated to pilots or to airborne or ground-based automation systems. The implementation of these shared SA systems offers controllers and pilots a common picture of the operational information necessary for them to perform their allocated roles and responsibilities. 
To transition to TBO operations it is crucial to determine the appropriate function allocation among the controller, the pilot, and automation in the flight deck and on the ground, and to determine what information should be shared between the controller and the pilot so that they can acquire and maintain sufficient shared situation awareness without being overloaded with information. These issues were preliminarily explored in this paper through the identification of the most relevant individual and shared information requirements (IR) for pilots and controllers for three specific tasks, and their interaction with each other as well as with automation for three viable function allocation concepts that are currently being investigated by NASA researchers [3],[4]. The results of this effort can be used as input to develop measurements of individual and shared situation awareness by probing the information that is most relevant to specific tasks, and to design experimental simulation studies that evaluate the viability of the function allocation concepts.

The rest of the paper is organized as follows. The next two sections describe the three function allocation concepts and the method used to elicit information from subject matter experts. The last section discusses the key findings and recommends ways to incorporate them into future studies and system design concepts.

\section{Function Allocation Concepts}

Three function allocation concepts that are currently being investigated by NASA and academic researchers were used as the context to elicit information from subject matter experts. These concepts were designed with a human-centered approach that allocates different functions (via roles and responsibilities) and workload levels among pilots, controllers and the automation in the flight deck and on the ground. Depending on the function allocation, the interaction between the controller and the pilot will be different, providing a rich area to study the sharing of SA information. These are the common assumptions for the three concepts:

1. All aircraft have the capability to communicate and exchange information with ATC through Controller Pilot Data Link Communications (CPDLC) and Automatic Dependent Surveillance Broadcasting (ADSB).

2. All aircraft have a cockpit situation display (CSD) on board integrated with a route assessment tool (RAT) and a 3D-weather display [5]. Using the RAT, the pilot can manually make changes to the trajectory to avoid conflicts and weather.

3. There are two groups of aircraft operating in the airspace: a) trajectory flight rule (TFR) aircraft have the capability to detect and resolve conflicts; and b) managed rule aircraft (MMR) are managed by ATC and do not have conflict detection capability.

4. Both TFR and MMR aircraft are involved in merging and spacing operations.

5. The ground and airborne auto-resolver system uses the NASA Advanced Airspace Concept (AAC) [6], [7] algorithm for detection and resolution of conflicts more than 12 minutes from loss of separation (LOS), and the Tactical Separation Assisted Flight Environment (TSAFE) algorithm for avoidance of conflicts less than 3 minutes to LOS. The auto-resolver tools on the ground and in the flight deck do not take weather into account; thus, pilots must ensure all resolutions are weather free. 
6. To resolve a conflict, the TFR pilot can use either the airborne auto-resolver on board to generate a conflict-free resolution and check for weather-free, or the RAT to do the same tasks. Similarly, the controller can use either the ground-based auto-resolver to generate resolutions and check for weather-free, or the manual trial planning tool to do the same tasks.

7. Rules of the road: TFR aircraft, when in conflict with MMR aircraft, are burdened to resolve the conflict. MMR aircraft are managed by ATC. For 3 minutes to LOS, TSAFE generates conflict-free resolution for all aircraft and informs the controller.

While these assumptions constitute an over-simplification of the system and its operation, they offer an effective means to explore the different levels of roles and responsibilities that can be allocated to controllers, pilots, and automation systems.

Concept 1: Shared Separation Assurance between ATC and Flight Decks. In this concept, the separation assurance responsibility is shared between the flight deck and ATC as shown in Figures 1a-1b.

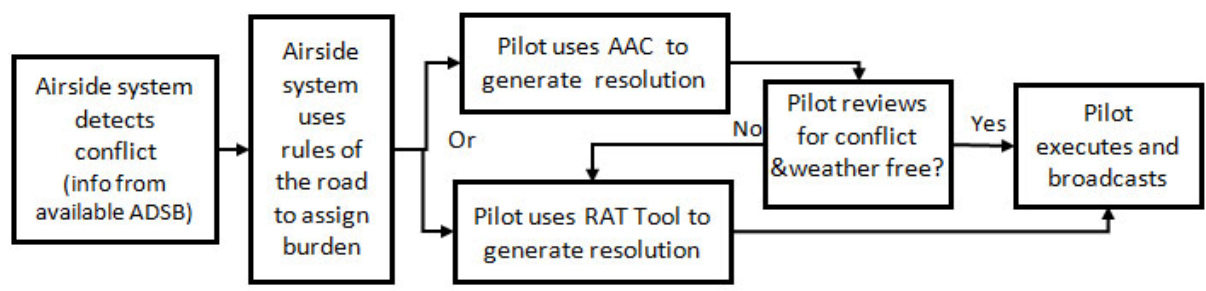

Fig. 1a. Flight deck is responsible for resolving conflicts 12-15 minutes to LOS between TFR and TFR aircraft, and TFR and MMR aircraft

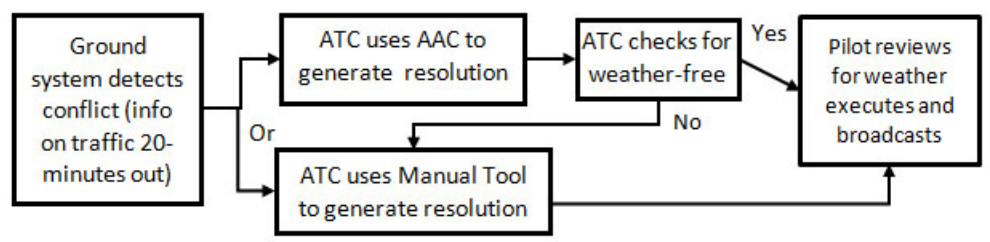

Fig. 1b. ATC is responsible for resolving conflicts 12-15 minutes to LOS between MMR and MMR aircraft

Concept 2: Separation Assurance by ATC with Delegation to Ground Automation. In this concept (shown in Figures 2a-2b), ATC is responsible for the separation assurance for all aircraft; however, to ease workload, ATC delegates the ground autoresolver to resolve conflicts between TFR and TFR aircraft, while ATC resolves conflicts between TFR and MMR aircraft, and between MMR and MMR aircraft. 


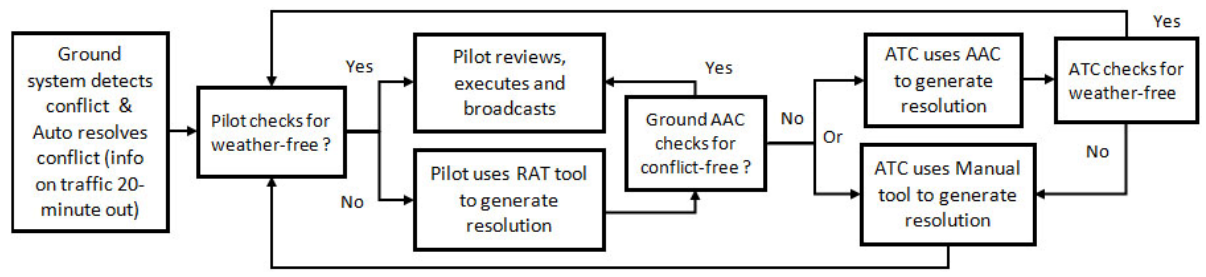

Fig. 2a. ATC is responsible for separation but delegates conflict resolution to ground autoresolver to resolve conflicts 12-15 minutes to LOS between TFR and TFR aircraft

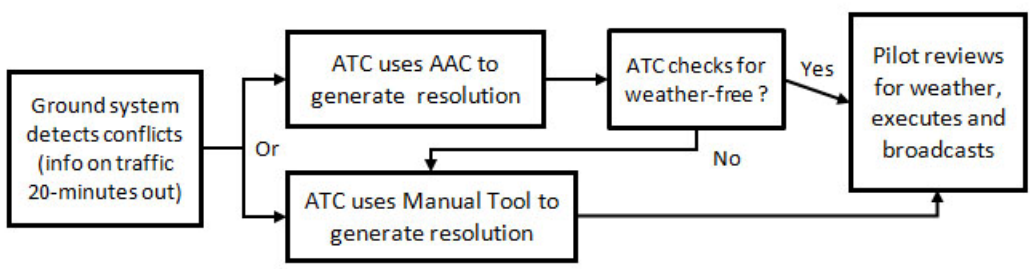

Fig. 2b. ATC is responsible for resolving conflicts 12-15 minutes to LOS between MMR and MMR aircraft, and between MMR and TFR aircraft

Concept 3: Separation Assurance by Ground Automation. In this concept (shown in Figures $3 \mathrm{a}$ and $3 \mathrm{~b}$ ), the ground auto-resolver has the responsibility for resolving conflicts between TFR and TFR aircraft, and between TFR and MMR aircraft. ATC is responsible for resolving conflicts between MMR and MMR aircraft.

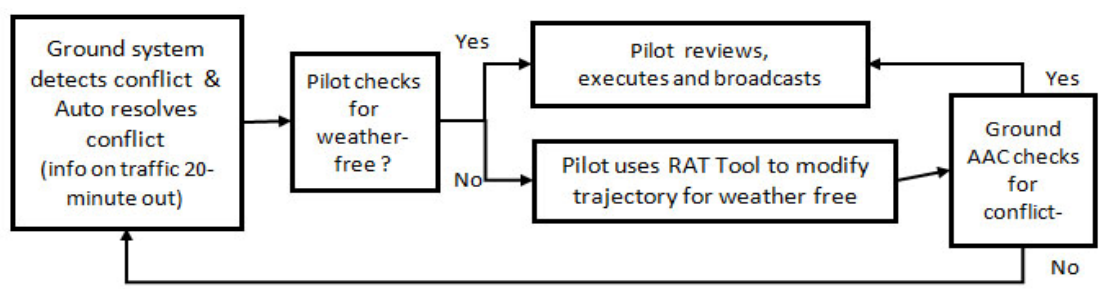

Fig. 3a. Ground auto-resolver is responsible for resolving conflicts 12-15 minutes to LOS between TFR and TFR aircraft, and between TFR and MMR aircraft

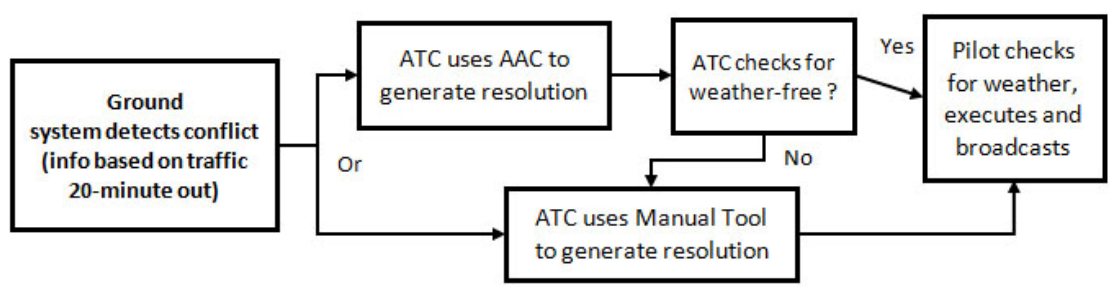

Fig. 3b. ATC is responsible for resolving conflicts 12-15 minutes to LOS between MMR and MMR aircraft 


\section{Elicitation Method}

The following three steps were used to develop the scenarios and tasks for the pilot and controller, and to elicit individual and shared IRs.

1. Create scenarios to depict the concepts and the three key tasks: Three key tasks formed the basis for developing the scenarios: 1) resolving aircraft conflicts; 2) avoiding weather; and 3) merging into a flow and spacing behind another aircraft. The scenarios, created and documented in video clips and pictures, describe the task flow diagrams (shown in Figures 1-3), the role and responsibility allocations, the interaction between the controller and the pilot, and the information and automation tools (e.g., AAC, TSAFE, CSD) available to perform the three tasks. In addition, the operation was assumed to take place in the Kansas City (ZKC) and Indianapolis (ZID) centers and Louisville International airport (KSDF) TRACON, with 36 aircraft (twice the current traffic level) flying a trajectory that goes through two high altitude sectors in ZKC, one high altitude and one low altitude sectors in ZID, the KSDF TRACON, and lands in KSDF airport.

2. Compile an information requirements list tractable for the elicitation: A list of IRs, shown in Tables 2 and 3, was compiled by extracting IRs documented in previous studies [8],[9],[10], which identified goals, sub-goals, and their associated individual and shared IRs for the commercial aircraft pilot and the air traffic controller. We selected the IRs to include in the list by their relevance to the three tasks, and asked the SMEs to provide any additional IRs that were not on the list.

\section{Elicit SMEs in individual sessions and in a group session to obtain the} information requirements: Two active airline pilots and two retired ATCs participated as subject matter experts (SME). The two ATP-rated pilots had an average of 8000 flight hours and the two retired controllers had an average of 37 years. All SMEs were familiar with both the ground and airborne automation tools and advanced displays (i.e., AAC, TSAFE, CSD, RAT) through their participation in past studies at NASA. In the individual sessions, the SME were interviewed for four hours and were given an introduction to the objective of the study and a detailed explanation of each function allocation concept (via task flow diagrams, pictures, and videos). Then, for each function allocation concept, the SME articulated their goal and sub-goal(s) for the tasks, identified any missing IRs in the provided list, and rated the level of necessity of the IRs (the rating scale is from 0 to 6 , with 0 being not necessary, and 6 being absolute necessary). The SMEs were also queried as to: a) how the IRs would change with each concept; b) their preference between using the automated auto-resolver versus the manual tools; and c) their perception of safety, efficiency, and workload for the concepts.

In the group session, the pilots and controllers were brought together and were queried as to: a) how they share information and work together to resolve a conflict, avoid weather, and merge aircraft; b) the extent to which the controller takes into consideration the objectives of the pilot, and vice versa; and c) whether the controller wants to be informed of TSAFE avoidance maneuvers. 


\section{Results and Discussion}

The goals and sub-goals for the three tasks in each concept are presented in Table 1 below. There was good agreement between the two pilots even though they fly for different airlines. The two controllers were also in good consensus. However, for the same high-level goals, the sub-goals of the pilots and the controllers have more differences than similarities. For instance, for the conflict resolution task, the pilots based their decision on the impact of the trajectory change on factors such as the fuel consumption, the time to destination, secondary conflicts, and passenger comfort. The controllers, on the other hand, based their decisions on factors such as the effect that the trajectory change has on the entire traffic flow, additional conflicts induced, and workload. Thus, while the controllers and the pilots shared common goals at the highest level, the controllers' motivations are system-centric, while the pilots are aircraft-centric. This was further reinforced in the group interview session in which the controllers confirmed that they rarely take into account the sub-goals that are important to the pilots, while the pilots indicated that they prefer the controllers to take into account as much as possible the sub-goals that are important to them.

The individual IRs for pilots and controllers, and the shared IRs, shown in bold, are listed in Tables 2 and 3. In general, across all concepts, altitude, heading, and speed were reported to be extremely necessary information, even in concept 3 where automation is responsible for handling the resolutions. These results ascertain which information is most needed for the three specific tasks, and should be useful in determining the most relevant information that should be probed when measuring individual and shared SA.

Some additional observations were noted regarding the feasibility of the concepts. First, for concept 1, the controllers identified the delegation of separation responsibility to TFR aircraft reduces performance monitoring (workload reduction); however, while assessing the costs and benefits of flight changes, traffic management negotiated with automation brought about more concern with the number of aircraft in the sector, handoffs, traffic inflow, and altitude limits in this concept than in concepts 2 and 3 . Second, in concept 2, ATC requested shared information about aircraft state, conflicts, and planned changes when managing traffic. This request is consistent with their comments that they perceived this concept to be more operationally complicated and workload intensive. This is because for situations in which the controllers have to step in to resolve a conflict, they thought they would not have enough time to react because a significant amount of time is used up for the pilot to determine a weather- and conflictfree resolution, for the ground auto-resolver to verify that the resolution is not conflict free. Thus, concept 2 was perceived to be the least favored of the three concepts due to the time delays. Third, in concept 3 , when the ground automation is delegated merging and spacing management, the pilot necessity ratings for the information about their aircraft and other aircraft were very low. This implies that the pilots' awareness can be low when they are not directly engaged with the merging and spacing operation, and that the pilot may be over reliant on the automation.

In the group session, the pilots and controllers indicated that maintaining continuous communications and exchanging information are key to developing a collaborative relationship and for effective decision making. But it was interesting to note that although the pilots preferred to share their sub-goals with the controllers, the controllers indicated that such sharing is not feasible because it would increase their 
workload. Hence, the pilots and controllers agreed that controllers do not always take into account pilots' sub-goals, and, as a result, pilots may have to fly routes that are non-optimal. It is also interesting to note that in situations such as concept 1 where the TFR pilots do not have to interact or share information with the controllers, the controllers indicated that they would like to be aware of the TFR trajectory changes so that if the TFR aircraft should merge with MMR aircraft, they can anticipate and plan for it. Finally, pilots and controllers indicated that the IRs do not change significantly with the concepts, but the priority of the information. These results suggest that when one measures shared SA, care must be taken to ensure that the shared information being probed is relevant to the intention of the human operators.

Table 1a. Pilots Goals and Sub-goals Across Function Allocation Concepts

\begin{tabular}{|c|c|c|c|c|}
\hline & & Concept 1 & Concept 2 & Concept 3 \\
\hline \multirow{2}{*}{$\begin{array}{l}\text { Task1: } \\
\text { Resolve } \\
\text { aircraft } \\
\text { conflict }\end{array}$} & Goals & $\begin{array}{l}\text { Aware of conflicts near and } \\
\text { far } \\
\text { Avoid secondary conflict }\end{array}$ & Avoid conflict & Avoid conflict \\
\hline & $\begin{array}{l}\text { Sub- } \\
\text { goals }\end{array}$ & $\begin{array}{l}\text { Fuel management } \\
\text { Time management } \\
\text { Manage alt/head } \\
\text { Communicate with ATC }\end{array}$ & $\begin{array}{l}\text { Fuel management } \\
\text { Passenger comfort } \\
\text { Communicate with } \\
\text { ATC }\end{array}$ & $\begin{array}{l}\text { Fuel management } \\
\text { Passenger comfort } \\
\text { Communicate with } \\
\quad \text { ATC }\end{array}$ \\
\hline \multirow{2}{*}{$\begin{array}{l}\text { Task 2: } \\
\text { Resolve } \\
\text { weather } \\
\text { conflict }\end{array}$} & Goals & Resolve conflict & Resolve conflict & Resolve conflict \\
\hline & $\begin{array}{l}\text { Sub- } \\
\text { goals }\end{array}$ & $\begin{array}{l}\text { Minimize weather impact } \\
\text { on passenger comfort } \\
\text { Fuel management }\end{array}$ & $\begin{array}{l}\text { Minimize weather } \\
\text { impact on passenger } \\
\text { comfort } \\
\text { Fuel management }\end{array}$ & $\begin{array}{l}\text { Fuel management } \\
\text { Minimize weather } \\
\text { impact on } \\
\text { passenger } \\
\text { comfort }\end{array}$ \\
\hline \multirow{2}{*}{$\begin{array}{l}\text { Task 3: } \\
\text { Merging } \\
\quad \text { \& } \\
\text { Spacing }\end{array}$} & Goals & $\begin{array}{l}\text { Spacing } \\
\text { Avoid creating conflicts }\end{array}$ & Spacing & Spacing \\
\hline & $\begin{array}{l}\text { Sub- } \\
\text { goals }\end{array}$ & $\begin{array}{l}\text { Fuel management } \\
\text { Time management }\end{array}$ & $\begin{array}{l}\text { Fuel management } \\
\text { Time management }\end{array}$ & $\begin{array}{l}\text { Fuel management } \\
\text { Time management }\end{array}$ \\
\hline
\end{tabular}

Table 1b. ATC Goals and Sub-goals Across Function Allocation Concepts

\begin{tabular}{|c|c|c|c|c|}
\hline & & Concept 1 & Concept 2 & Concept 3 \\
\hline \multirow{2}{*}{$\begin{array}{l}\text { Task1: } \\
\text { Resolve } \\
\text { aircraft } \\
\text { conflict }\end{array}$} & Goals & Separation & Separation & Separation \\
\hline & $\begin{array}{l}\text { Sub- } \\
\text { goals }\end{array}$ & $\begin{array}{l}\text { Reduce workload: } \\
\text { Communicate less }\end{array}$ & $\begin{array}{l}\text { Reduce workload: } \\
\text { Communicate less } \\
\text { Sector traffic }\end{array}$ & $\begin{array}{l}\text { Fuel levels for } \\
\text { sequence priority } \\
\text { Reduce sector } \\
\text { workload }\end{array}$ \\
\hline \multirow{2}{*}{$\begin{array}{l}\text { Task 2: } \\
\text { Resolve } \\
\text { weather } \\
\text { conflict }\end{array}$} & Goals & $\begin{array}{l}\text { Separation } \\
\text { Weather avoidance }\end{array}$ & $\begin{array}{l}\text { Separation } \\
\text { Weather avoidance }\end{array}$ & $\begin{array}{l}\text { Separation } \\
\text { Weather avoidance }\end{array}$ \\
\hline & $\begin{array}{l}\text { Sub- } \\
\text { goals }\end{array}$ & $\begin{array}{l}\text { Weather details } \\
\text { (ie.temps,percip, wind ) }\end{array}$ & $\begin{array}{l}\text { Communicate less } \\
\text { Reduce sector workload } \\
\text { Know vertical speed }\end{array}$ & $\begin{array}{l}\text { Communicate } \\
\text { Monitor weather }\end{array}$ \\
\hline \multirow{2}{*}{$\begin{array}{c}\text { Task 3: } \\
\text { Merging } \\
\text { \& } \\
\text { Spacing }\end{array}$} & Goals & Separation & Spacing & Spacing \\
\hline & $\begin{array}{l}\text { Sub- } \\
\text { goals }\end{array}$ & $\begin{array}{l}\text { Fuel management } \\
\text { Sequence priority } \\
\text { Know a./c (speed,alt,hdg) }\end{array}$ & $\begin{array}{l}\text { Fuel management } \\
\text { Sequence priority }\end{array}$ & $\begin{array}{l}\text { Fuel management } \\
\text { Sequence priority }\end{array}$ \\
\hline
\end{tabular}


Table 2. Pilot Information Requirements

Pilot Information Requirements

\begin{tabular}{|c|c|c|c|c|c|c|c|c|}
\hline & \multicolumn{3}{|c|}{ Concept 1} & \multicolumn{3}{|c|}{ Concept 2} & \multicolumn{2}{|c|}{ Concept 3} \\
\hline & Traffic & Weather & $\mathbf{M} \& \mathbf{S}$ & Traffic & Weather & M \& S & Traffic & Weather \\
\hline \multicolumn{9}{|l|}{ Current Ownship state } \\
\hline ID & 3.5 & 1.5 & 2.5 & 3 & 3 & 3 & 3 & 3.5 \\
\hline Heading & 4.5 & 6 & 5.5 & 5.5 & 5.5 & $\mathbf{5}$ & $\mathbf{5}$ & 5.5 \\
\hline Speed & 4.5 & 5.5 & 5.5 & 5.5 & 5 & 5 & 5.5 & 5.5 \\
\hline Ver. Speed & 4.5 & 5 & 3.5 & 4 & 4 & 3 & 4 & 5 \\
\hline Alt. & 6 & 6 & 6 & 6 & 6 & 5.5 & 5.5 & 6 \\
\hline Attitude & 4 & 5 & 4.5 & 5 & 4.5 & 5 & 4.5 & 4.5 \\
\hline Immediate destination & 1.5 & 2 & 2.5 & 3.5 & 4 & 4 & 3.5 & 3 \\
\hline Route & 5 & 4.5 & 4.5 & 5 & 4.5 & 5 & 4.5 & 4 \\
\hline \multicolumn{9}{|l|}{ Ownship Planned Changes } \\
\hline Heading changes & 2.5 & 0 & 0 & 2 & 2 & 2 & 5 & 5 \\
\hline speed changes & 2 & 0 & 0 & 2 & 2 & 2 & 5 & 5 \\
\hline Alititude Changes & 2.5 & 0 & 0 & 3 & 2.5 & 2.5 & 5.5 & 5.5 \\
\hline Route Changes & 2.5 & 0 & 0 & 2.5 & 2.5 & 2.5 & 4.5 & 4.5 \\
\hline \multicolumn{9}{|l|}{ Future Ownship State } \\
\hline Future Hor. Pos. & 3 & 2 & 2.5 & 2 & 2 & 2 & 2 & 2 \\
\hline Future heading & 5 & 5 & 5 & 4.5 & 5 & 5 & 5 & 5 \\
\hline Future Speed & 4.5 & 5 & 5 & 4.5 & 5 & 5 & 4.5 & 5 \\
\hline Future ver. Speed & 2.5 & 4.5 & 3.5 & 3.5 & 4 & 3.5 & 3 & 4 \\
\hline Future altitude & 5 & 5 & 5.5 & 5 & 5.5 & 5.5 & 5.5 & 5.5 \\
\hline Future destination & 5 & 3.5 & 3 & 4.5 & 4.5 & 4.5 & 4.5 & 4.5 \\
\hline Future route & 5 & 4.5 & 4 & 5 & 4.5 & 4.5 & 5 & 4.5 \\
\hline \multicolumn{9}{|l|}{ Cost/benefit of change in } \\
\hline Lateral Flight & 5.5 & 4 & 3.5 & 5 & 3.5 & 3 & 4.5 & 3.5 \\
\hline Vertical flight & 5.5 & 4 & 3.5 & 5 & 3.5 & 3 & 4.5 & 3.5 \\
\hline Speed profile & 5 & 4 & 3 & 5 & 3.5 & 3 & 4.5 & 3 \\
\hline Holding vs. diverting & 5.5 & 5.5 & 4.5 & 5 & 5 & 4.5 & 5 & 5 \\
\hline level of automation & 0 & 3.5 & 0 & 0 & 4 & 0 & 0 & 3 \\
\hline \multicolumn{9}{|l|}{ Other Aircraft State } \\
\hline ID & 3.5 & 0 & 4 & $\overline{4}$ & 0 & 6 & 4.5 & $\overline{0}$ \\
\hline Hor. Pos. & 3 & 0 & 2.5 & 2.5 & 0 & 3 & 2.5 & 0 \\
\hline Heading & 5.5 & 0 & 5 & 5 & 0 & 5 & 5 & 0 \\
\hline Speed & 5.5 & 0 & 5 & 5 & 0 & 5 & 5 & 0 \\
\hline Vert. Speed & 5 & 0 & 2.5 & 3 & 0 & 3.5 & 3.5 & 0 \\
\hline altitude & 6 & 0 & 5.5 & 6 & 0 & 6 & 6 & 0 \\
\hline Immediate destination & 3 & 0 & 3.5 & 4 & 0 & 3.5 & 2.5 & 0 \\
\hline Route & 4.5 & 0 & 4 & 4 & 0 & 4 & 4 & 0 \\
\hline Priority & 5 & 0 & 3.5 & 4 & 0 & 4 & 4.5 & 0 \\
\hline \multicolumn{9}{|l|}{ Other Aircraft Future State } \\
\hline Future Hor. Pos. & 2.5 & 0 & 2 & 2 & 0 & 2.5 & 2.5 & $\overline{0}$ \\
\hline Future Heading & 5.5 & 0 & 5 & 4.5 & 0 & 5 & 5 & 0 \\
\hline Future Speed & 5.5 & 0 & 5 & 4.5 & 0 & 5 & 5 & 0 \\
\hline Future Vertical speed & 4.5 & 0 & 3 & 3 & 0 & 3 & 3.5 & 0 \\
\hline Future Altitude & 5.5 & 0 & 5.5 & 5.5 & 0 & 5.5 & 5.5 & 0 \\
\hline Future Immediate Destination & 3 & 0 & 3.5 & 3.5 & 0 & 3 & 3.5 & 0 \\
\hline Future Route & 4.5 & 0 & 4.5 & 4 & 0 & 3 & 4.5 & 0 \\
\hline Future Priority & 5 & 0 & 3.5 & 4 & 0 & 4 & 5 & 0 \\
\hline \multicolumn{9}{|l|}{ Weather } \\
\hline Location of Weather cells & 0 & 6 & 0 & $\overline{0}$ & 6 & 0 & 0 & $\overline{6}$ \\
\hline Altitudes affected & 0 & 5.5 & 0 & 0 & 5.5 & 0 & 0 & 6 \\
\hline Temperature & 0 & 3.5 & 0 & 0 & 4 & 0 & 0 & 4 \\
\hline Dewpoint & 0 & 1.5 & 0 & 0 & 3.5 & 0 & 0 & 3.5 \\
\hline Precipitation level & 0 & 4.5 & 0 & 0 & 5 & 0 & 0 & 5.5 \\
\hline Precipitation type & 0 & 5 & 0 & 0 & 5 & 0 & 0 & 5.5 \\
\hline Visibility & 0 & 5 & 0 & 0 & 5.5 & 0 & 0 & 5 \\
\hline Ceiling & 0 & 5 & 0 & 0 & 5.5 & 0 & 0 & 5 \\
\hline Wind direction & 0 & 5.5 & 0 & 0 & 4.5 & 0 & 0 & 5.5 \\
\hline Wind speed & 0 & 5.5 & 0 & 0 & 4.5 & 0 & 0 & 5.5 \\
\hline Wind rate of change & 0 & 4.5 & 0 & 0 & 4.5 & 0 & 0 & 4.5 \\
\hline Wind altitutdes & 0 & 5 & 0 & 0 & 4.5 & 0 & 0 & 5 \\
\hline Wind gusts & 0 & 5.5 & 0 & 0 & 5.5 & 0 & 0 & 5.5 \\
\hline Wind crosswind component & 0 & 4 & 0 & 0 & 3 & 0 & 0 & 3.5 \\
\hline Conf. in weather cond. & 0 & 5.5 & 0 & 0 & 5 & 0 & 0 & 5.5 \\
\hline Timeliness of info & 0 & 5.5 & 0 & 0 & 5 & 0 & 0 & 4.5 \\
\hline path of min. weather exposure & 0 & 5.5 & 0 & 0 & 5 & 0 & 0 & 5 \\
\hline Distance to weather areas & 0 & 5.5 & 0 & 0 & 5 & 0 & 0 & 5.5 \\
\hline Bearing to weather areas & 0 & 5.5 & 0 & 0 & 5 & 0 & 0 & 5.5 \\
\hline
\end{tabular}


Table 3. ATC Information Requirements

ATC Information Requirements

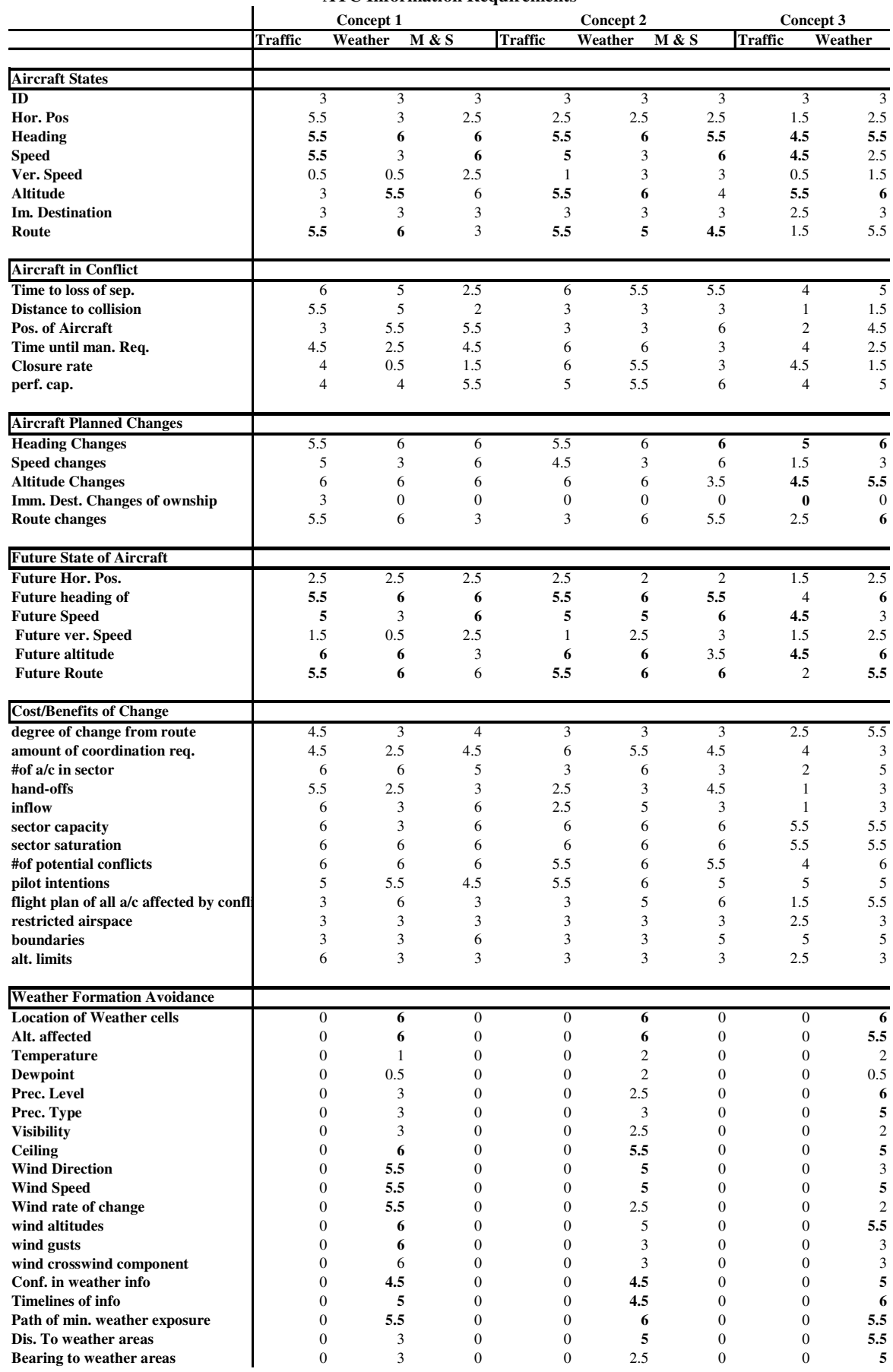


The pilots and controllers also provided input as to their interaction with the automation. In general, the SMEs believed that trust must be developed with the automation tools, otherwise these concepts would not be feasible. In the situations with three minutes to LOS and TSAFE has to generate conflict avoidance maneuvers, both the pilots and controllers felt strongly that a good form of automation design and function allocation would have TSAFE notify the controllers of the resolution to prevent the aircraft from getting into more conflicts and prepare to insert the aircraft back into the flow. In addition, during high-pressure the pilots and controllers preferred to use the auto-resolver (airborne or ground) over the manual RAT tool, making the automation tools become more critical.

In future simulation studies when the concepts are evaluated, it would be fruitful to compare these perceptions and observations provided by the SMEs against the simulation's quantitative data. The comparison would help identify discrepancies or agreements, and provide further insights into the feasibility of the concepts.

Acknowledgement. The authors would like to thank Dr. Walter Johnson, Mr. Vernol Battiste, Mr. Quang Dao of NASA Ames for the development and clarification of the function allocation concepts.

\section{References}

1. Joint Planning and Development Office: Next Generation Transportation System: Concept of Operation V 2.0. Washington D.C: Government Printing Office (2007)

2. Next Generation Air Transportation System (NGATS) Air Traffic Management (ATM) Airportal Project,

http: //www.aeronautics.nasa.gov/nra_pdf /

airportal_project_c1.pdf

3. McNally, D., Gong, C.: Concept and Laboratory Analysis of Trajectory-Based Automation for Separation Assurance. AIAA-2006-6600, AIAA Guidance, Navigation and Control Conference and Exhibit, Keystone, CO, August 21-24 (2006)

4. Prevot, T.: Controller-in-the-Loop Evaluation of Ground-Based Automated Separation Assurance. In: NASA Airspace Systems Technical Interchange Meeting (2008)

5. NASA Ames Flight Deck Display Research Laboratory, http: / / human-factors.arc.nasa.gov/ihh/cdti/cdti.html

6. Erzberger, H.: Automated conflict resolution for air traffic control. In: Proceedings of the 25th International congress of the aeronautical sciences (ICAS), Hamburg, Germany, September 3-8 (2006)

7. Erzberger, H.: Transforming the NAS: The next generation air traffic control (2004)

8. Endsley, M.R., Farley, T.C., Jones, W.M., Midkiff, A.H., Hansman, R.J.: Situation Awareness Information Requirements for Commercial Airline Pilots (ICAT-98-1). Massachusetts Institute of Technology International Center for Air Transportation, Cambridge (1998)

9. Endsley, M.R., Jones, D.G.: Situation awareness requirements analysis for TRACON air traffic control (TTU-IE-95-01). Lubbock, TX: Texas Tech University (1995)

10. Endsley, M. R., Rodgers, M. D.: Situation awareness information requirements for en route air traffic control (DOT/FAA/AM-94/27). Washington, D.C.: Federal Aviation Administration Office of Aviation Medicine (1994) 